\title{
Efeitos da inter-cloração na duração da carreira de filtração e na formação de THM em águas de abastecimento
}

\section{Effects of the inter-chlorination in the filtration run and THM formation in drinking water treatment}

\author{
Davi Rodrigues da Silva* \\ Químico pela Universidade de Brasília (UnB). Mestre em Bioquímica pela Universidade \\ de Brasília (UnB). Atualmente é Químico da CAESB-DF.
}

\section{Noêmia Célia Milhomem Costa}

Graduada em Administração pela Faculdade de Ciências Sociais e Tecnológicas, pós-graduada em Perícia, Auditoria e Gestão Ambiental pela Faculdade Oswaldo Cruz. Atualmente é Técnica em Saneamento da Caesb.

\section{Lúcio Flávio C. Magalhães}

Químico pela Universidade de Brasília (UnB). Atualmente é Químico da CAESB-DF.

\section{Cínthia Mesquita P. Cavalcanti}

Química pela Universidade de Brasília (UnB). Especialização em Saneamento Ambiental pelo

Instituto Formação para Educação. Atualmente é Química da CAESB-DF.

\section{Luiz Antonio Daniel}

Graduação em Engenharia Civil pela Universidade Federal de Minas Gerais, UFMG, Brasil. Mestrado em Engenharia Civil EESC-USP pela Universidade de São Paulo, USP, Brasil. Doutorado em Engenharia Civil EESC-USP pela Universidade de São Paulo, USP, Brasil. Atualmente é Professor Doutor MS3 da Universidade de São Paulo.

*Endereço para correspondência: QNM 42 ÁREA ESPECIAL - M NORTE - TAGUATINGA NORTE - DISTRITO FEDERAL DF - CEP: 72200-000 - Brasil - Tel: (61) 34913217 - e-mail: drs1_rodrigues_76@yahoo.com.br. dias_joel@hotmail.com

\section{RESUMO}

A etapa de filtraçáo no processo de tratamento de água para abastecimento público foi avaliada utilizando um sistema de filtraçáo composto por camada suporte de pedregulho e areia. O filtro, constituído de areia com diâmetro dos grăos de 0,89 e $0,59 \mathrm{~mm}$ e altura do leito de 50 e $125 \mathrm{~cm}$, foi alimentado com água decantada proveniente de um flocodecantador, operado com taxa de filtraçáo de $21 \mathrm{~m}^{3} \cdot \mathrm{m}^{-2} \cdot \mathrm{dia}^{-1}$ e avaliado em termos de turbidez e evoluçáo de perda de carga. Para aumentar a eficiência da filtraçáo foi inserida a intercloraçáo e semanalmente, durante 18 meses, monitorou-se a concentração de THM. Esta fase de oxidação foi adicionada para melhorar o aproveitamento da estação de tratamento de água, o que também trouxe grande contribuição ambiental, pois aumentou a carreira de filtração e o tempo de lavagem, diminuindo significativamente as perdas de água e a quantidade de lodo produzido na estação, cuja disposição final deverá atender a legislação ambiental vigente.

Palavras-Chave: água de abastecimento, cloração, filtração.

\section{ABSTRACT:}

The filtration step in water treatment process for public waterworks was assessed using a filtration system composed of gravel and sand layer support. The filter, consisting of sand with grain diameter of 0.59 and 0.89 
$\mathrm{mm}$ and bed height of 50 and $125 \mathrm{~cm}$, respectively, was fed with water from a sludge blanket flocculate decanter, operated with filtration rate of $21 \mathrm{~m}^{3} \cdot \mathrm{m}^{-2}$. day $^{-1}$ and assessed in terms of turbidity and evolution of head loss. To increase the efficiency of filtration the inter-chlorination was introduced and weekly, during 18 months, THM concentration in the affluent and effluent was monitored. This oxidation step was added to improve the utilization of the water treatment plant, which also brought great environmental contribution, because increased filtration's run and the washing time, significantly decreasing the loss of water and the amount of sludge produced at the drinking water treatment plant, whose final disposition must meet current environmental legislation.

Keywords: treatment process, inter-chlorination, filtration.

\section{INTRODUÇÃO}

$\mathrm{O}$ processo de tratamento de água pode ser visto como um conjunto de operaçóes aplicadas à água em suas mais diferentes fontes com o objetivo de torná-la apta para abastecimento público. Para tanto, significa afirmar que a sua qualidade físico-química e microbiológica atende a certos Padróes de Qualidade definidos por agências reguladoras.

Atualmente, mananciais para abastecimento público de grandes centros urbanos vem recebendo esgoto doméstico e efluentes industriais sem tratamento, decorrente do crescimento populacional desordenado e da falta de investimentos para coleta e tratamento desses efluentes. Paralelamente, em determinadas épocas do ano, devido ao aumento da frequência, intensidade e duraçấo das precipitaçôes atmosféricas, o escoamento superficial resultante carreia grande quantidade de partículas e matéria orgânica dissolvida ocasionando aumento da turbidez e cor da água bruta nas estaçôes de tratamento de água.

A filtraçáo é a última operaçáo unitária empregada na remoção de material particulado e coloidal presente na água bruta, sendo assim, esta assume importância significativa na produção de água potável. Tipicamente, os sistemas de filtraçáo empregados no tratamento de água de abastecimento podem ser classificados de acordo com a sua localização na sequência das operaçóes da estação de tratamento de água (filtração em linha, filtração direta ou do tipo de ciclo completo), sentido de escoamento (descendente e ascendente), materiais filtrantes (areia, antracito, carvão ativado granular), arranjo do material filtrante (camada simples, dupla camada e, eventualmente, tripla camada), taxa de filtração (filtração lenta e rápida) e controle hidráulico (DI BERNARDO, 1993). O principal objetivo da filtraçấo de águas de abastecimento é a remoção de material particulado que possa produzir efluente com qualidade organoléptica não adequada para fins de consumo e a relação com a saúde pública ao reter microrganismos patogênicos.

Historicamente, o agente oxidante mais empregado em processos de tratamento de água tem sido o "cloro", na forma de cloro gasoso $\left(\mathrm{Cl}_{2}\right)$, hipoclorito de sódio $(\mathrm{NaOCl})$ e hipoclorito de cálcio $\left(\mathrm{Ca}(\mathrm{OCl})_{2}\right)$ (DEGRÉMONT, 1979; MONTGOMERY, 2005). Por ser um agente oxidante, o derivado clorado livre pode reagir com compostos orgânicos sintéticos e naturais, participando de reaçóes de oxidação e substituiçáo, em que átomos de cloro podem ser adicionados às moléculas denominadas precursoras, formando compostos orgânicos clorados denominados subprodutos da desinfecçấo (SPD) (HERBERT et al, 2010). As reaçôes que envolvem o cloro residual livre e os compostos orgânicos naturais sáo extremamente complexas, uma vez que estes apresentam uma elevada diversidade de grupos funcionais aromáticos, carboxílicos, fenólicos, bem como grandes quantidades de duplas e triplas ligaçóes e que são passíveis de serem atacadas pelo agente oxidante.

Os subprodutos da desinfecção com o derivado clorado são, principalmente, os trialometanos (THM), ácidos haloacéticos (HAA), haloacetonitrilas (HAN) e cloropicrinas. A formaçấo de THM aumenta com a concentração de cloro residual livre, concentração de substâncias húmicas, temperatura e pH (PAVÓN et $a l, 2008)$. Muitos deles têm sido classificados como prováveis ou possíveis substâncias carcinogênicas para os seres humanos e têm sido regulados pela Agência Americana de Proteção Ambiental (USEPA) desde 1996, pela Organização Mundial de Saúde (WHO) desde 1995 e pela Comunidade Econômica Européia (CEE) em 1998. As propriedades toxicológicas e epidemiológicas dos SPD têm sido amplamente estudadas. À exposiçáa aos compostos orgânicos clorados, sobretuto THM, está associado ao aumento de risco de câncer, particularmente na bexiga e reto (HEBERT et al, 2010). A IARC (Agência Internacional para Pesquisa do Câncer) classificou o clorofórmio e o bromodiclorometano como cancerígenos potenciais a humanos (Grupo 2B) e o dibromoclorometano e 
bromofórmio como cancerígeno de potencial limitado (Grupo 3B) (PAVÓN, et al, 2008; WAG et al, 2007; WHO, 2006).

Entretanto, a partir dos primeiros resultados acerca da efetividade do cloro como agente desinfetante e de sua aplicabilidade prática no tratamento de águas de abastecimento, estabeleceu-se a necessidade de que, qualquer que fosse a modalidade de tratamento adotada, a etapa de desinfecçáo teria que ser necessariamente incorporada.

A água de lavagem de filtros, em ETAs, apresenta também, normalmente, risco ambiental e potencial de poluição, visto que sáo utilizadas substâncias muitas vezes tóxicas e/ou inflamáveis que após os processos químicos normalmente geram "lixo tóxico" que precisa ser tratado (resíduo) e dado um descarte apropriado. Sendo assim, uma diminuição deste resíduo proporciona vantagem ambiental e econômica.

Com o objetivo de proporcionar a melhoria da filtraçăo, desinfecção e diminuiçáo da produção de lodo buscouse a alternativa de instalaçâo da intercloraçấo em uma estação de tratamento de água. Para isto foram realizados ensaios para quantificação da concentração de alumínio remanescente ao longo do processo, monitoramento de THM por meio da cromatografia gasosa, testes de perda de carga dos filtros e estimativa da quantidade de água de lavagem produzida antes e após a intercloraçáo ser implantada.

\section{MATERIAIS E MÉTODOS}

\section{Filtro}

Para a avaliaçáo da etapa de filtração foi utilizado um filtro composto por camada suporte de pedregulho e areia. Este filtro é alimentado por água decantada proveniente de um flocodecantador e operado com taxa de filtraçáo de $21 \mathrm{~m}^{3} \cdot \mathrm{m}^{-2} \cdot \mathrm{dia}^{-1}$. O meio filtrante é constituído de areia com diâmetro dos gráos de 0,89 e $0,59 \mathrm{~mm}$ e altura do leito de 50 e $125 \mathrm{~cm}$, respectivamente. O filtro foi avaliado em termos de turbidez da água filtrada e evoluçáo de perda de carga. O filtro, em formato cilíndrico, com estrutura construída em aço-carbono com as dimensóes $1,2 \mathrm{~m}$ de diâmetro e 2,4 metros de altura, foi operado com pressáo de trabalho de 1,8-2,0 kgf.cm ${ }^{-2}(200 \mathrm{kPa})$.
Após a lavagem efetuava-se a primeira coleta de amostras de água filtrada. Durante a primeira hora, as coletas de amostras de água filtrada foram efetuadas de $15 \mathrm{em}$ 15 minutos. Do mesmo modo, efetuou-se a primeira leitura do manômetro no filtro. Encerrada a primeira hora de operaçáo após a lavagem as amostras passaram a ser coletadas de hora em hora. A seguir, verificava-se a vazão de alimentaçấo. Quando não atendida esta vazẫo efetuou-se seu ajuste pelo rotâmetro confirmando-a por mediçáo volumetricamente. A vazáo do filtro foi verificada a cada quatro horas, aproximadamente, a fim de se assegurar a taxa de filtração desejada.

O encerramento da carreira de filtraçáo foi determinado quando ocorreu pelo menos uma das seguintes condiçóes:

- Turbidez da água filtrada maior ou igual a 0,5 uT em três medidas consecutivas;

-Carreira de filtraçẫo com máximo de 40 horas;

-Duraçáo da carreira do filtro realizada com base na pressấo interna do filtro quando se chegava a $22 \mathrm{kgf}$. $\mathrm{cm}^{-2}(2,2 \mathrm{MPa})$.

Uma vez encerrada a carreira de filtração, fechavam-se os registros de entrada de água decantada de alimentaçáo do filtro. Em seguida procedia-se sua lavagem conforme descrito a seguir:

Abria-se o registro de saída de água de lavagem e aplicava-se água em contracorrente de modo a permitir a expansāo do material filtrante. Para tanto, procediase a abertura lenta e gradual da válvula de aplicação de água de forma a evitar a separaçáo do leito filtrante. Essa aplicaçáo de água era efetuada por, pelo menos, 10 minutos.

Neste experimento, realizou-se também a inserção de um ponto de intercloraçáo, ou seja, antes da entrada do filtro e após o decantador.

\section{DETERMINAÇÁO DE THM}

Para uma melhor eficiência da filtração foi instalado um sistema com intercloraçáo (cloraçáo antes do filtro) e semanalmente, durante 18 meses, monitorouse a concentraçáo de THM. Esta fase de oxidaçáo foi 
inserida visando melhor aproveitamento da estaçáo, o que também trouxe grande contribuição ambiental, pois aumentou a carreira de filtraçáo e o tempo de lavagem diminuindo significativamente a quantidade de lodo produzido na estaçấo, assim como as perdas de água. $\mathrm{O}$ derivado clorado, na forma de hipoclorito de sódio, foi aplicado antes do filtro (intercloração), em dosagem que manteve cloro residual livre de 1,2 mg. $\mathrm{L}^{-1}$, mensurado pela técnica DPD, após tempo de contato médio de 24 a 48 horas. A amostra de água tratada para análise de THM foi coletada e mantida em frasco âmbar de volume de $40 \mathrm{~mL}$, com tampa rosqueada de material inerte, preferencialmente teflon, ou de plástico revestido com teflon de forma a evitar o contato da água com a tampa plástica.

O frasco continha três gotas de solução de ácido ascórbico $(25 \mathrm{mg} / 40 \mathrm{~mL}$ ) para CG/MS ou mesmo volume de tiossulfato de sódio $(3 \mathrm{mg} / 40 \mathrm{~mL})$. Foi necessário realizar a coleta completando o frasco até a boca com a amostra, fechando-o com cuidado de modo a evitar formaçấo de bolhas e a presença de oxigênio.

O transporte da amostra foi realizado sob refrigeração e o tempo para o processamento da análise foi de três dias, atendendo a recomendação para preservação. A amostra refrigerada foi entáo transferida para o frasco de vidro de $40 \mathrm{~mL}$, com septo de PTFE/silicone, sendo fechado de forma a evitar formaçáo de bolha. Inseriu-se a amostra no auto-amostrador, ou injetou-se, utilizando uma seringa apropriada, que transferiu o volume de 5 $\mathrm{mL}$ desta diretamente no aparelho de purge and trap, com volume de $5 \mathrm{~mL}$. O volume utilizado no autoamostrador foi de $5 \mathrm{~mL}$ da amostra e os parâmetros a serem determinados eram: (por ordem de saída no cromatograma) Clorofórmio, Diclorobrometano, Dibromoclorometano e Bromofórmio. A soma das concentraçôes de cada um dos THM constitui o valor de THM total. Os cromatogramas obtidos foram integrados e as respectivas áreas nos tempos de retenção de cada composto foram calculadas por meio de curvas de calibração previamente existentes as quais se encontravam no arquivo do software "Lab Solutions" que acompanha o aparelho em questáo (cromatógrafo a gás com espectrômetro de massas).

As condiçóes de uso do cromatógrafo a gás com espectrômetro de massas acoplado foram: temperatura inicial do forno $40{ }^{\circ} \mathrm{C}$, mantida por dois minutos, em seguida, aquecimento numa taxa de $6^{\circ} \mathrm{C} /$ minuto até $140{ }^{\circ} \mathrm{C}$, mantendo essa temperatura por um minuto. Temperatura do injetor $180^{\circ} \mathrm{C}$, pressáo total de 13,5
$\mathrm{kPa}$, fluxo $\mathrm{He}$ de $7,5 \mathrm{~mL} /$ minuto, Velocidade linear de $45 \mathrm{~mL} /$ minuto, purga de $3 \mathrm{~mL} /$ minuto e split de 2,0. Para o espectrômetro de massa (MS) os controles foram os seguintes: temperaturas na fonte de íons 200 ${ }^{\circ} \mathrm{C}$ e na interface $250{ }^{\circ} \mathrm{C}$, faixa de massa de 35 a 300 amu e dois scan por segundo. O cromatógrafo utilizado foi o modelo QP 2010 plus da Shimadzu, associado a um autoamostrador Solatek 72 e um aparelho de Purge and Trap Velocity XPT da mesma marca. O tempo de contato médio foi de 24 a 48 horas e o cloro residual livre de $1,2 \mathrm{mg} \cdot \mathrm{L}^{-1}$. O teor final de THM foi entáo calculado pelo somatório de cada um de seus quatro componentes, ou seja, as concentraçóes de Clorofórmio $\left(\mathrm{CHCl}_{3}\right), \quad$ Bromodiclorometano $\left(\mathrm{CHCl}_{2} \mathrm{Br}\right)$, Clorodibromometano $\left(\mathrm{CHClBr}_{2}\right)$ e Bromofórmio $\left(\mathrm{CHBr}_{3}\right)$.

\section{RESULTADOS DA PRIMEIRA ETAPA}

A etapa de filtração foi executada após a otimização do processo de coagulação e floculação. Após vários testes de jarros e dados da própria estaçấo, constatou-se que a maior eficiência de coagulaçăo ocorreu em pH entre 6,0 a 6,5 e dosagens de sulfato de alumínio variando entre 2 a 5 mg.L $\mathrm{L}^{-1}$. Primeiramente, avaliou-se o desempenho do filtro sem o processo de oxidaçẫo/intercloraçáo. A variaçấo da turbidez ao longo da carreira de filtraçáo está representada na figura 1 . O ensaio de filtração foi realizado após as condiçôes do processo de coagulaçáo permanecerem próximas aos resultados otimizados pelo teste de jarros. De acordo com a figura 1 a turbidez da água bruta, decantada e filtrada manteve-se relativamente constante com valores próximos a 15; $2 \mathrm{e}$ $0,4 \mathrm{uT}$, respectivamente. A eficiência de remoção média da filtração variou entre 95 e 99\% para turbidez, cor aparente e sólidos suspensos totais. A evolução de perda de carga é consequência direta da retençáo de partículas coloidais pelos filtros e, deste modo, quanto maior for à concentração de partículas coloidais no afluente, maior será a taxa de crescimento de perda de carga. Com isto, observando-se a figura 2, nota-se que a perda de carga chegou ao limite da pressão interna de $22 \mathrm{kgf.cm}^{-2}(2,2$ $\mathrm{MPa})$ em 24 horas.

Entretanto, neste experimento, realizou-se a inserção de intercloração, ou seja, após o decantador e antes da entrada do filtro. Esta dosagem foi mantida, para fim de estabilizaçáo e limpeza do leito filtrante, por 48 horas seguidas. As coletas de amostras foram feitas somente após este tempo de operaçẫo. A intercloração aplicada após o decantador e antes do filtro não resultou em mudança significativa na turbidez das 


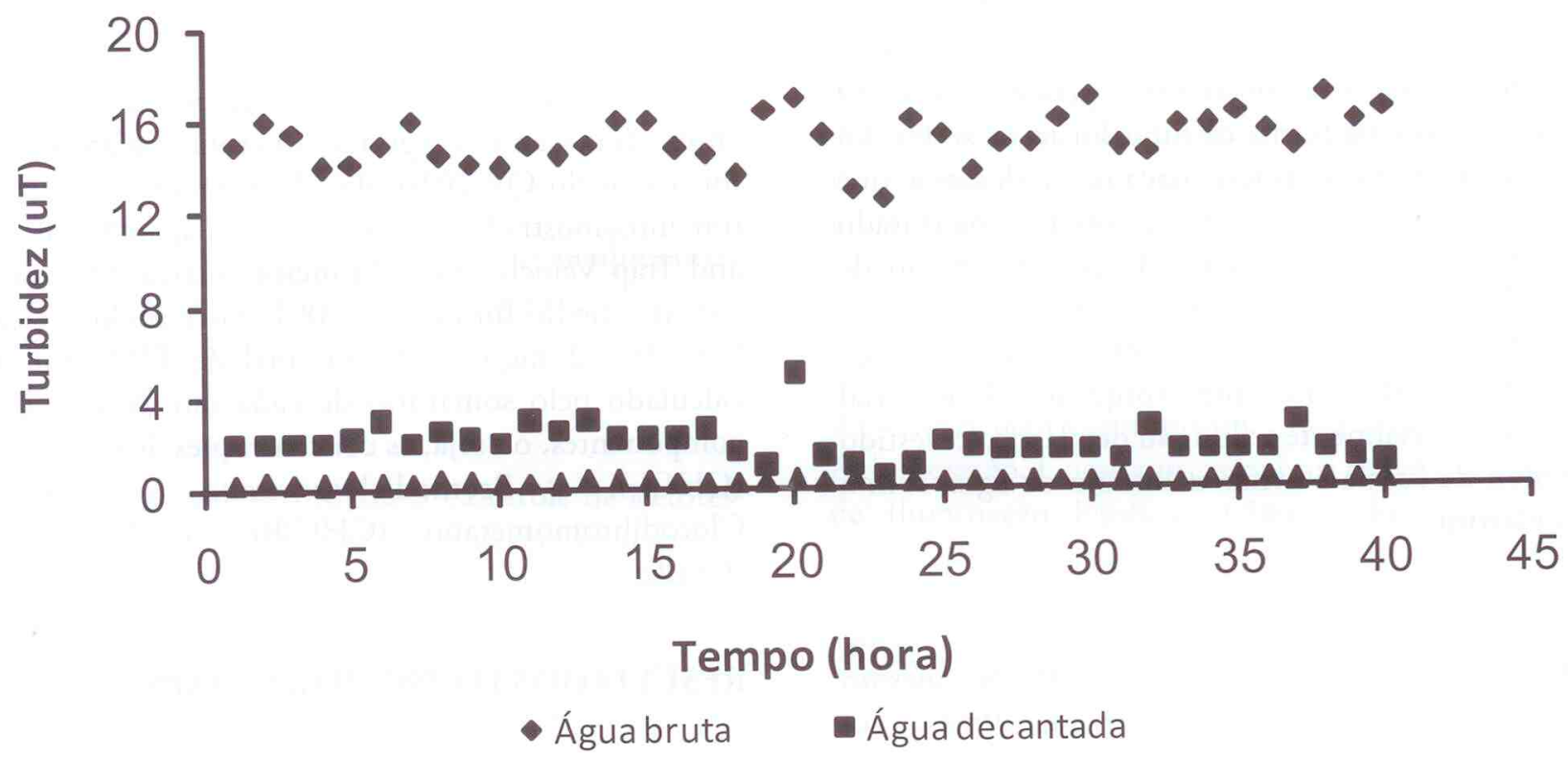

Figura 1: Relaçấo da turbidez em funçáo do tempo da carreira de filtração para o filtro em tempo de estiagem.

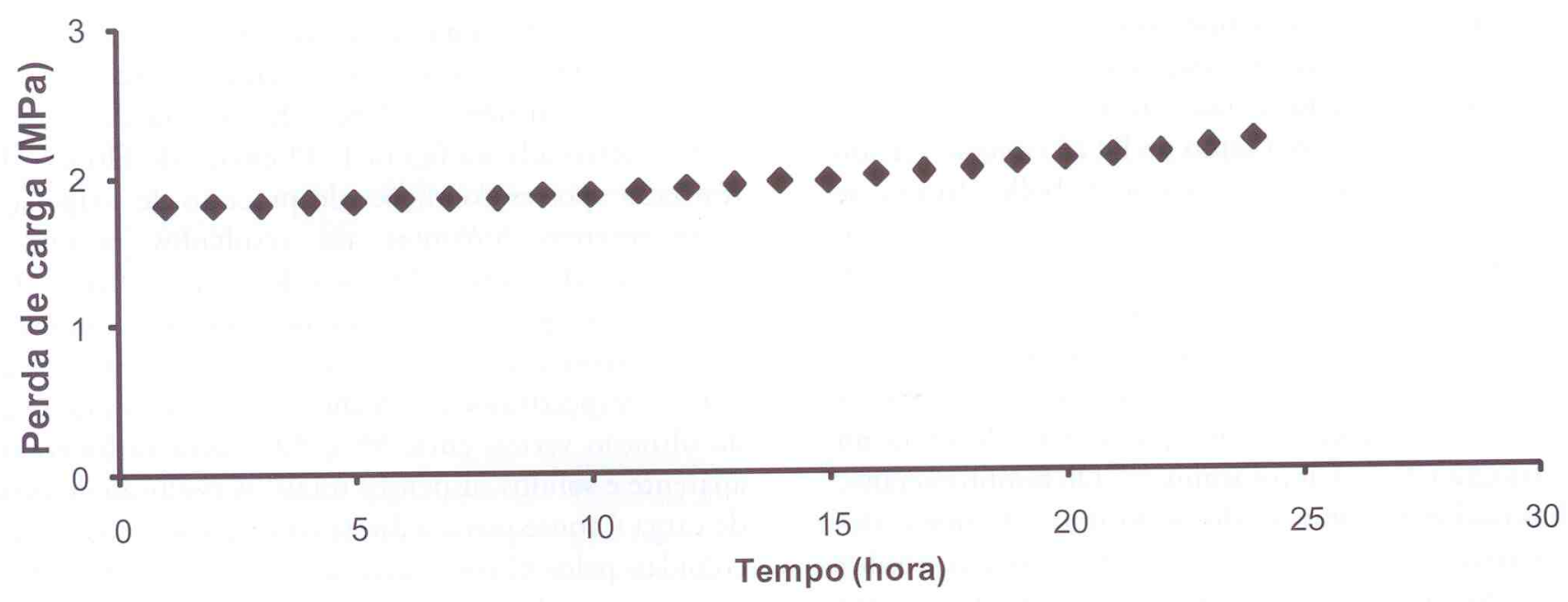

Figura 2: Perda de carga em funçấo do tempo (horas) para o filtro em tempo de estiagem.

águas bruta, decantada e filtrada em relaçáo ao ensaio sem a intercloraçáo, como representado na figura 3. A intercloraçấo aumentou a duração da carreira de filtração, pois de acordo com a figura 4 a pressão interna do filtro chega ao limite de $22 \mathrm{kgf}$. $\mathrm{cm}^{-2}(2,2 \mathrm{MPa})$ em 40 horas, com 18 horas a mais do que sem a intercloraçáo. As partículas coloidais apresentam carga elétrica negativa e os gráos que compóem o meio filtrante, na grande maioria dos casos, apresentam também carga elétrica negativa.
A aproximação de uma partícula contendo uma determinada carga elétrica ocasionará uma interaçáo entre as suas duplas camadas. Caso a partícula possua carga negativa, esta interaçáo será repulsiva. Por outro lado, se possuir carga positiva a interaçấo será atrativa. Por isto, tendo em vista que as partículas coloidais na água apresentam carga negativa e os grãos do material filtrante também, o processo de filtração somente será efetivo se as partículas coloidais forem coaguladas anteriormente ao processo de filtração. $\mathrm{O}$ derivado 


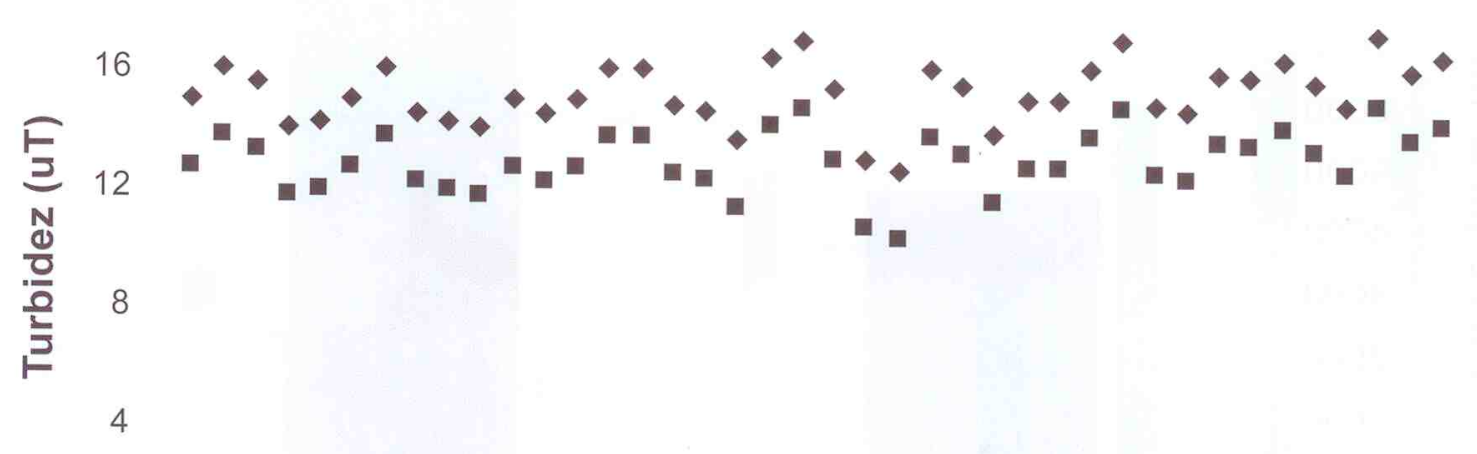

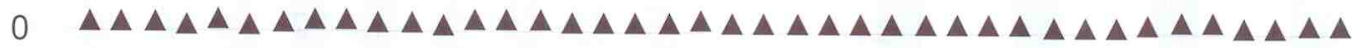 $\begin{array}{lllllllll}0 & 5 & 10 & 15 & 20 & 25 & 30 & 35 & 40\end{array}$
Tempo (hora)

- Água bruta $\mathbf{m}$ Água decantada $\Delta$ Água Filtrada

Figura 3: Relaçấo da turbidez em função do tempo da carreira de filtraçáo para o filtro em tempo de estiagem com o processo de oxidação/intercloração.

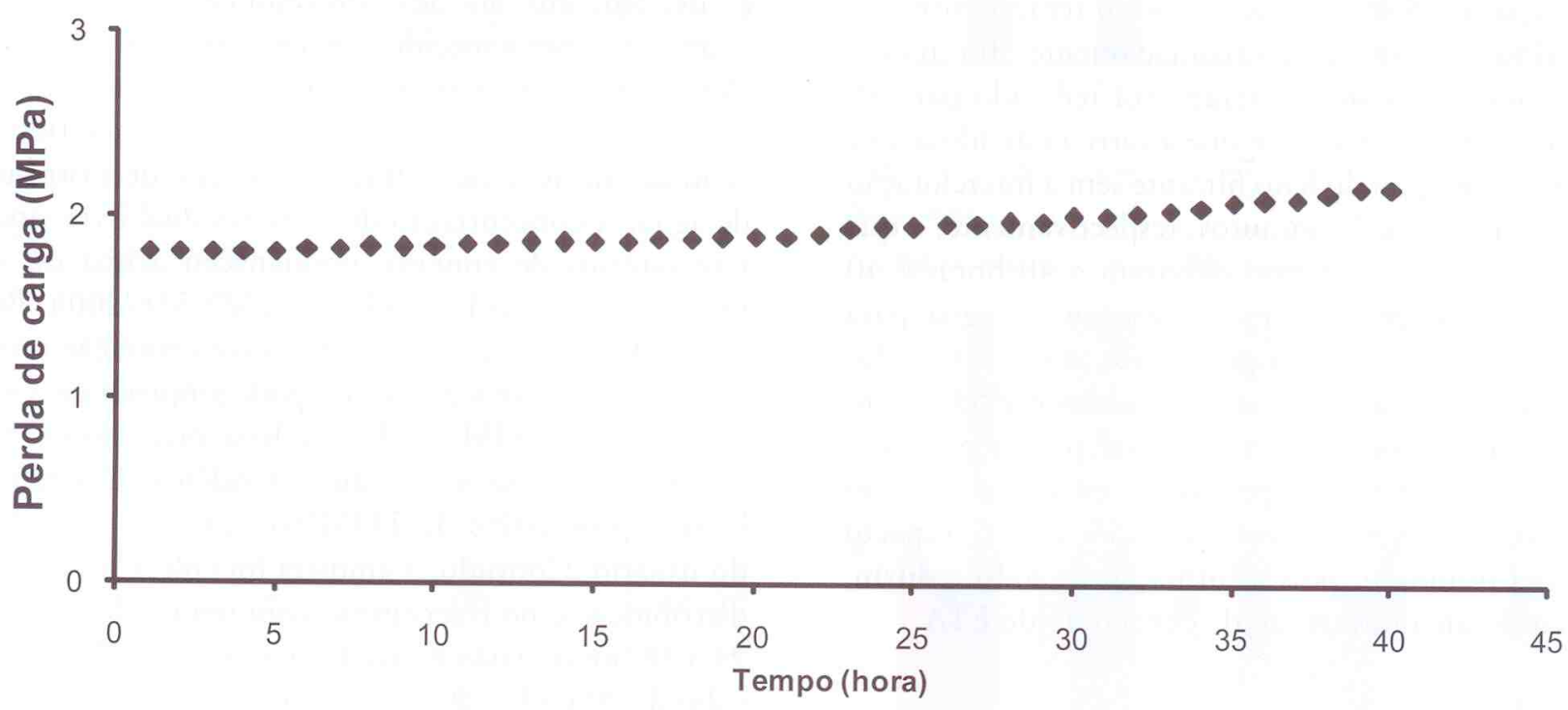

Figura 4: Perda de carga (kgf.cm-2) em funçáo do tempo (horas) para o filtro em tempo de estiagem com ponto de intercloração.

clorado auxilia na oxidação e quebra das moléculas, como também na mudança de carga elétrica do leito filtrante, contribuindo para um melhor rendimento do filtro (LAUBUSCH, E. J., 1971).

A fim de estabelecer o quanto o aumento da carreira de filtração trouxe benefícios para a estação de tratamento de água estudada fez-se um gráfico comparativo do volume de água gasto no processo de lavagem do leito filtrante.
Estimando-se que antes da inclusáo do processo de intercloraçáo a carreira do leito filtrante era de 24 horas e após a inclusão passou a ser de 40 horas e que o tempo de lavagem do leito filtrante permaneceu igual a 50 minutos, o volume de água gasto para lavagem do filtro em um ano sem a intercloraçáo será de $7774,5 \mathrm{~m}^{3}$ e com a inclusão do processo de intercloração será de 4600,8 $\mathrm{m}^{3}$, resultando em redução de aproximadamente $40 \%$, conforme representado na figura 5 . Estes valores foram 


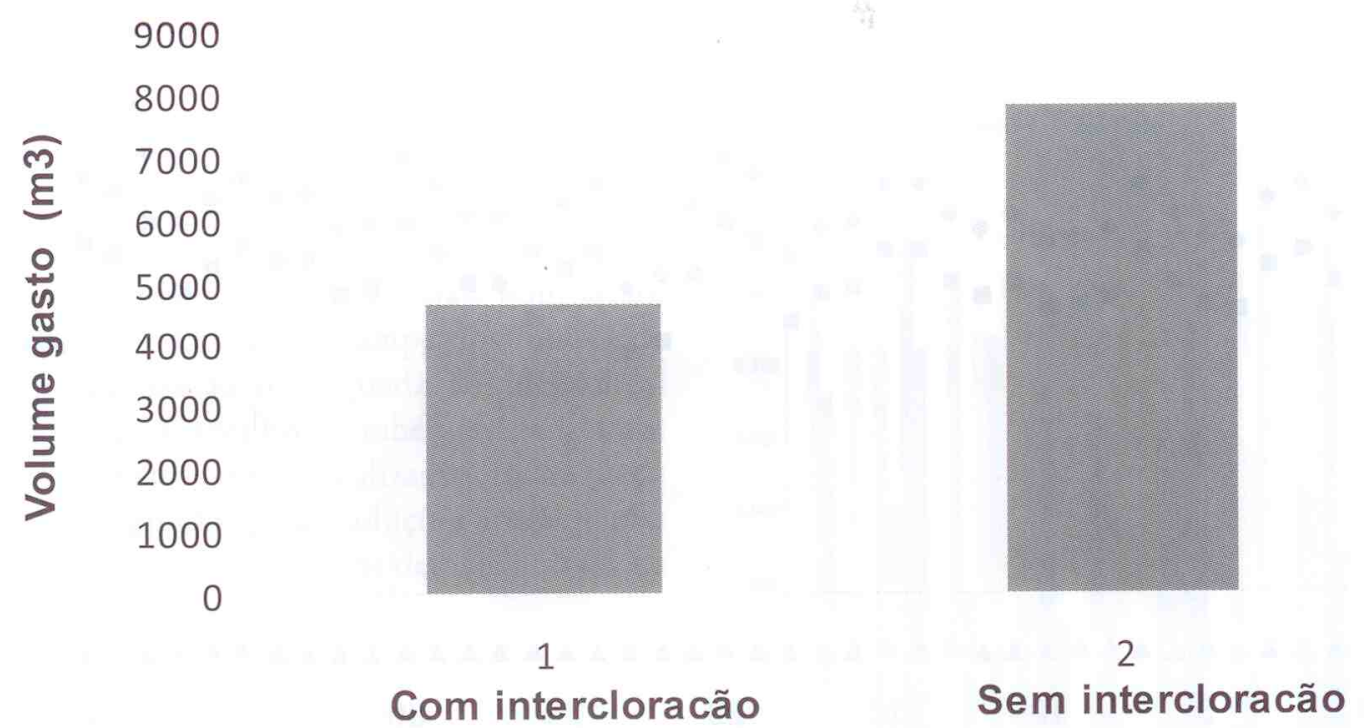

Figura 5: Volume gasto em metros cúbicos no processo de lavagem de filtro com e sem intercloraçáo.

estimados, pois a ETA não funciona continuamente 24 horas por dia, havendo períodos de interrupçáo do tratamento devido à existência de reservatório que abastece a rede de distribuição de água. Além disto, o tempo de lavagem do leito filtrante foi reduzido com a intercloração. Sem a intercloraçấo, o tempo estimado de lavagem do leito é de aproximadamente 50 minutos e com a intercloraçáo este tempo foi reduzido para 40 minutos. Tomando por base que a carreira de filtraçáo e o tempo de lavagem do leito filtrante sem a intercloraçáa eram de 24 horas e 50 minutos, respectivamente, e que com a inserção do processo passaram a 40 horas e 40 minutos, a economia com o consumo de água para lavagem do filtro será superior aos $40 \%$ estimados anteriormente, passando a aproximadamente 53\%. Isto acarretou uma economia considerável para o processo, além de diminuiçấo nas perdas da estaçấo e reduçấo na formação de água de lavagem. Com isto, o impacto ambiental diminuiu, pois a formaçáo de lodo reduziu, acarretando uma nova visão de concepçấo de ETA.

No ano de 1974, de acordo com Dunnick et al.,(1993) os THMs foram detectados na água potável nos Estados Unidos e estudos da época apresentaram as primeiras indicaçốes da existência de correlação entre água de abastecimento, THMs e câncer e, estudos posteriores, levaram à fixação de valores máximo permissíveis. Os principais fatores que influenciam a formação de THM săo: tempo de contato, temperatura, $\mathrm{pH}$, característica e concentração da matéria orgânica, dosagem do derivado clorado aplicado, cloro residual livre e concentraçáo de brometos (SINGER, 1994). Na figura 6 está representada a concentração de THM em função das datas de coleta. Observa-se que durante os 18 meses em que este subproduto foi monitorado náo houve valores acima de 0,1 mg. $\mathrm{L}^{-1}$, conforme estabelecido no Brasil, pela Portaria MS 518/2004 (Brasil, 2004). A referida Portaria estabelece que na saída da ETA, a água deve conter teor mínimo de cloro residual livre de $0,5 \mathrm{mg} . \mathrm{L}^{-}$ ${ }^{1}$, após ter permanecido em contato com o derivado clorado por um período mínimo de 30 minutos nos reservatórios de contato e deverá ser mantido um residual mínimo de $0,2 \mathrm{mg} \cdot \mathrm{L}^{-1}$ na rede de distribuiçáo de água. A concentraçấo de cloro residual livre, após os reservatórios de contato, permaneceu acima do valor mínimo estabelecido pela Portaria MS 518/2004 (Brasil, 2004). Isto por um lado garante a concentração mínima exigida na rede, mas por outro, pode propiciar uma maior formaçáo de THM desde que haja precursores. Nesse contexto, pode-se inferir que a tendência é o aumento lento e progressivo de THM na água, até a residência do usuário. Contudo, a amostra foi coletada na rede de distribuiçáo e no reservatório com tempo de contato de 24 a 48 horas, e năo houve formação de THM acima do valor de $20 \mu \mathrm{g} . \mathrm{L}^{-1}$, demonstrando que a concentraçấo de THM está abaixo dos limites estabelecido pela Portaria MS 518/2004 (Brasil, 2004).

\section{Conclusôes}

O cloro aplicado entre o decantador e o filtro intercloraçấo - reagiu com o material do meio filtrante e alterou a carga elétrica da superfície dos grãos resultando em maior eficiência de retenção das partículas suspensas na água, maior duração da carreira de filtração e menor tempo de lavagem do filtro. 


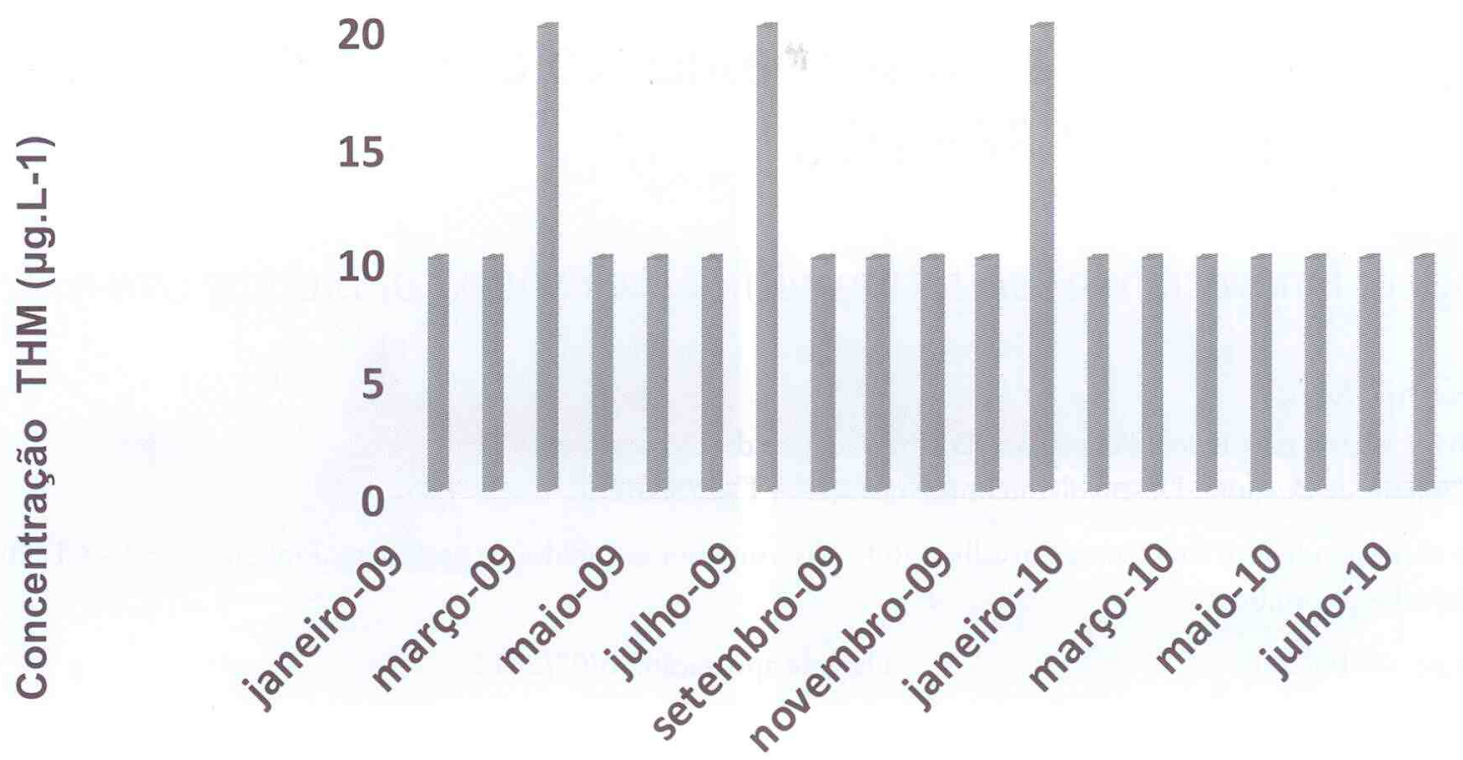

Figura 6: Concentração de THM com intercloração na água após o tanque de contato e tempo de contato de 48 horas.

A economia no consumo de água de lavagem do filtro resultante da associaçẫo dessas alterações será de aproximadamente $53 \%$.

A concentraçáo de THM formada para a dosagem de cloro utilizada na intercloração, considerando as características físicas e químicas da água utilizada no estudo, permaneceu abaixo de $20 \mu \mathrm{g} \mathrm{L}^{-1}$.

\section{REFERÊNCIAS}

1-APHA, AWWA, Standard Methods for the Examination of Water And Wastewater, 21 ed., 2005 BRASIL, MINISTÉRIO DA SAÚDE. Normas e padrão de potabilidade das águas destinadas ao consumo humano. Portaria no. 518/GM, Brasília, Brasil, março de 2004.

2-DEGRÉMONT, 1979. Water Treatment Handbook. New York: John Wiley \& Sons.

3-DI BERNARDO, L. Métodos e técnicas de tratamento de água. Volume II, 503p. Rio de Janeiro, ABES, 1993.

4-DUNNICK JK, Melnic RL. Assesment of the carcinogenic potential of chlorinated water: experimental studies of chlorine, chloramine, and trihalomethanes. J Natl Cancer Inst. v.85, p 817-22, 1993.

4-FERREIRA FILHO, S. S. Fluidificação e Expansâo de
Meios Filtrantes Duplos Constituídos de Areia-Antracito e Areia-Carvão Ativado Granular. In: $18^{\circ}$ Congresso Brasileiro de Engenharia Sanitária e Ambiental, Rio de Janeiro: Associação Brasileira de Engenharia Sanitária e Ambiental, 1995.

5-LAUBUSCH, E. J., 1971. Chlorination and other disinfection processes. In: Water Quality and Treatment: A Handbook of Public Water Supplies (American Water Works Assocciation), pp.158-224, New York: McGrawHill Book Company.

6-MONTGOMERY, J. Water treatment: principles and design. New York, John Wiley \& Sons, 2a Edição, 1.948 p., 2005.

7-USEPA - U.S. ENVIROMENTAL PROTECTION AGENCY. Guidance manual alternative disinfection and oxidants. Washington, DC. 1999, 346 p.

8-SINGER, P.C. Control of disinfection by-products in drinking water. Journal of Environmental Engineering, American Society of Civil Engineers. v. 120, n. 4, p. 727-744, 1994.

9-WHO - World Health Organization. Guidelines for Drinking-water Quality [electronic resource] incorporating first addendum. Vol. 1, Recommendations - 3rs ed. 1995. Disponível online em <http://www. who.int/water_sanitation_health/dwq/guidelines/en/>. Acesso em: 18 ago. 2006. 